\title{
Application of Physiologically Based Pharmacokinetic Modeling to Predict the Effect of Renal Impairment on the Pharmacokinetics of Olanzapine and Samidorphan Given in Combination
}

\author{
Lei Sun ${ }^{1}\left(\mathbb{D} \cdot\right.$ Lisa von Moltke ${ }^{1} \cdot$ Karen Rowland Yeo $^{2}$ \\ Accepted: 13 November 2020 / Published online: 14 December 2020 \\ (c) The Author(s) 2020
}

\begin{abstract}
Background A combination of the antipsychotic olanzapine and opioid receptor antagonist samidorphan (OLZ/SAM) is in development for the treatment of patients with schizophrenia or bipolar I disorder. The effect of severe renal impairment on the pharmacokinetics of olanzapine and samidorphan after a single oral dose of OLZ/SAM was evaluated in a clinical study. Complementary to the clinical findings, physiologically based pharmacokinetic modeling was used to assess the effects of varying degrees of renal impairment on the pharmacokinetics of olanzapine and samidorphan.

Methods A physiologically based pharmacokinetic model for OLZ/SAM was developed and validated by comparing modelsimulated data with observed clinical data. The model was applied to predict changes in olanzapine and samidorphan pharmacokinetics after administration of OLZ/SAM in subjects with mild, moderate, and severe renal impairment relative to age-matched controls with normal renal function.

Results The model predicted 1.5- and 2.2-fold increases in olanzapine and samidorphan area under the plasma concentration-time curve (AUC), respectively, after a single dose of OLZ/SAM in subjects with severe renal impairment vs controls, which was consistent with results from the clinical study. Application of the model prediction indicated increases in steadystate olanzapine AUC of 1.2-, 1.5-, and 1.6-fold, and samidorphan AUC of 1.4-, 1.8-, and 2.2-fold, in subjects with mild, moderate, and severe renal impairment, respectively, relative to healthy controls.

Conclusions Physiologically based pharmacokinetic modeling extended the findings from a clinical study in severe renal impairment to other untested clinical scenarios; these data could be of interest to clinicians treating patients with renal impairment.
\end{abstract}

\section{Introduction}

A combination of olanzapine and samidorphan, an opioid receptor antagonist [1-3], is in development for the treatment of patients with schizophrenia or bipolar I disorder. The addition of samidorphan to olanzapine (OLZ/SAM) is intended to provide the established antipsychotic efficacy of olanzapine [4-9] while mitigating olanzapine-associated weight gain [10].

The pharmacokinetics of olanzapine and samidorphan has been characterized after oral administration of either compound alone or in combination [11-14]. Olanzapine is

Lei Sun

lei.sun@alkermes.com

1 Clinical Pharmacology, Alkermes, Inc, 852 Winter Street, Waltham, MA 02451, USA

2 Simcyp Division, Certara UK Limited, Sheffield, UK mainly eliminated via direct glucuronidation and cytochrome P450 (CYP)-mediated hepatic metabolism; only 7\% of the administered dose is excreted renally as unchanged olanzapine [15]. Samidorphan is eliminated primarily via CYP3A4mediated hepatic metabolism, with approximately $20 \%$ of the administered dose being excreted renally as unchanged samidorphan [16]. It was of interest to investigate the effect of renal impairment (RI) on the pharmacokinetics of olanzapine and samidorphan because schizophrenia and bipolar disorder have been associated with increased risks of chronic kidney disease (CKD) [17, 18], and RI can affect the clearance of both renally and non-renally cleared drugs [19, 20].

Physiologically based pharmacokinetic (PBPK) modeling was initially applied to predict the effect of varying degrees of RI on the pharmacokinetics of olanzapine and samidorphan after OLZ/SAM administration. However, given that the concept of using PBPK modeling to prospectively predict drug pharmacokinetics in subjects with RI has not been 


\section{Key Points}

Physiologically based pharmacokinetic (PBPK) modeling was used to assess the impact of renal impairment on the pharmacokinetics of olanzapine and samidorphan given in combination (OLZ/SAM).

Model-predicted changes in pharmacokinetic parameters aligned with those observed in a clinical study that evaluated the effect of severe renal impairment on the pharmacokinetics of olanzapine and samidorphan.

Use of PBPK modeling allowed for the prediction of the effects of mild, moderate, and severe renal impairment on the steady-state pharmacokinetics of olanzapine and samidorphan after multiple-dose administration of OLZ/ SAM in lieu of additional clinical studies.

systematically established [21], a clinical study was conducted to evaluate the effect of RI and to verify the PBPK modeling predictions. Because neither olanzapine nor samidorphan is predominantly renally eliminated, only severe RI was evaluated in the clinical study [16], where any change in clearance would be most pronounced.

In that study, severe RI resulted in decreases of olanzapine and samidorphan clearance of $33 \%$ and $56 \%$, respectively, after a single dose of OLZ/SAM $5 \mathrm{mg} / 10 \mathrm{mg}(5 / 10)$ [16]. Consistent with the decrease in clearance, area under the plasma drug concentration-time $(C-T)$ curve from time 0 to infinity $\left(\mathrm{AUC}_{0-\infty}\right)$ was increased 1.51- and 2.31-fold, while maximum concentration $\left(C_{\max }\right)$ was increased 1.32 and 1.37-fold for olanzapine and samidorphan, respectively, in subjects with severe RI relative to healthy control subjects. To expand upon the single-dose pharmacokinetic findings from the OLZ/SAM clinical study in severe RI to other untested clinical scenarios, PBPK modeling was verified against existing clinical data and used to predict the effect of mild, moderate, and severe RI on the steady-state pharmacokinetics of olanzapine and samidorphan after multipledose administration of OLZ/SAM.

\section{Methods}

The PBPK modeling reported here consisted of three reiterative steps, as outlined in Fig. 1 and described in detail below.

\subsection{Model Development}

Separate PBPK models for olanzapine and samidorphan were developed in the Simcyp Simulator (Certara, Princeton,
NJ, USA) as described previously [22]. Briefly, a minimal PBPK model was used for olanzapine that included a single adjusting compartment combining all tissues except the intestine, liver, and portal vein (Fig. 2a). A full PBPK model, which included additional tissues such as adipose, brain, bone, heart, lung, muscle, and skin, was used for samidorphan (Fig. 2b). These models were selected because they described the disposition of each component of OLZ/ SAM with reasonable accuracy when compared with existing clinical data. A minimal PBPK model was adequate for describing the disposition of olanzapine, while a full PBPK model led to improved recovery of the observed halflife of samidorphan. The input parameters for each model have been previously described [22] and are presented in Table 1. These parameters take into account available in vitro metabolism and in vivo clinical data, such as plasma protein binding, Caco- 2 cell permeability, interaction with P-glycoprotein, absorption rate kinetics, enzyme effects, and other pharmacokinetic data [23-26]. Both olanzapine and samidorphan were assumed to have first-order absorption kinetics, as first-order models were able to capture the absorption profiles of both olanzapine and samidorphan adequately.

Elevated serum creatinine levels indicate varying levels of RI [27]. Within the Simcyp Simulator, a serum creatinine value $(\mu \mathrm{mol} / \mathrm{L})$ was generated for each individual from a lognormal distribution defined by a mean and coefficient of variation (depending on the RI category). This value was then used in the Cockcroft-Gault equation to estimate creatinine clearance $(\mathrm{mL} / \mathrm{min})$. The creatinine clearance was divided by a value of 120 or 130 for female and male patients, respectively, to determine a scalar of renal function, which was then applied directly to the renal plasma clearance input. A mean serum creatinine level of $105 \mu \mathrm{mol} / \mathrm{L}$ (with a corresponding coefficient of variation of $9 \%$ ) was applied to generate appropriate levels in a population with mild RI [27]. The corresponding parameters for moderate and severe RI were the default values of the Sim-RenalGFR_30-60 and RenalGFR_less_30 populations, respectively (Table 2).

Anemia develops as a consequence of CKD, and decreased hemoglobin and/or hematocrits have been reported for male and female patients with CKD [28, 29]. For mild RI, moderate RI, and severe RI, hematocrit values of $39.7 \%, 39.7 \%$, and $33.2 \%$ were applied to male patients, respectively, and hematocrit values of $36.5 \%, 36.5 \%$, and $31.3 \%$ were applied to female patients, respectively (Table 2) [28, 29].

Changes in drug plasma protein binding are often observed in mild, moderate, and severe RI owing to decreased levels of albumin (a direct consequence of hyperalbuminuria in subjects with CKD) or an increase in plasma levels of alpha acid glycoprotein [30]. Within the Simulator, depending on the main binding protein, the generated 


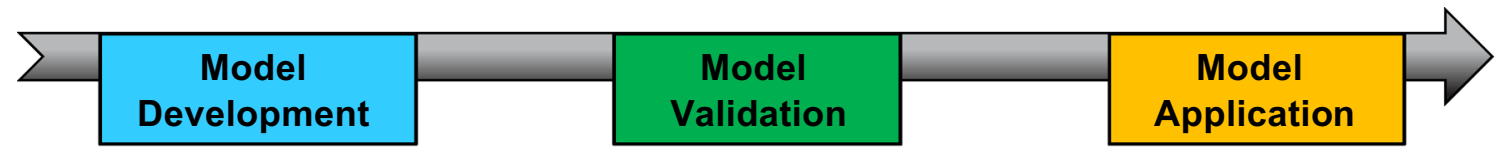

- Develop separate
PBPK models for
olanzapine and
samidorphan with
physiochemical
properties, in vitro and
in vivo ADME, and
clinical PK data
Optimize the models as
needed with additional
in vitro and clinical PK
data

- Verify PBPK models for
each compound and in
combination (OLZ/SAM)
using observed single-
and multiple-dose PK
data in healthy subjects
and patients with
schizophrenia given each
compound alone or in
combination
- Compare model-predicted
effect of severe RI on PK
of OLZ/SAM with observed
single-dose PK data

- Apply the validated
PBPK model for
OLZ/SAM to
prospectively predict
the change in steady-
state systemic
exposures of each
compound in subjects
with mild, moderate,
and severe RI relative
to healthy controls

pharmacokinetic (PBPK) modeling. ADME absorption, distribution, metabolism and excretion

Fig. 1 Schematic workflow for predicting the effect of renal impairment (RI) on the pharmacokinetics (PK) of olanzapine and samidorphan given in combination as OLZ/SAM, using physiologically based

albumin or alpha acid glycoprotein levels $([P])$ for a disease population may be used against a reference value for healthy subjects $\left([P]_{\text {pop }}\right)$ to calibrate the fraction unbound (fu) for the latter $\left(\mathrm{fu}_{\mathrm{pop}}\right)$ to a disease population value $(\mathrm{fu})$, according to the following equation:

$\mathrm{fu}=\frac{1}{1+\left[\frac{[P]}{[P]_{\text {pop }}} \times \frac{\left(1-\mathrm{fu}_{\text {pop }}\right)}{\mathrm{fu}_{\mathrm{pop}}}\right]}$.

The default values of the healthy volunteer library were used for the generation of albumin levels in virtual subjects with mild RI. The corresponding parameters for moderate and severe RI were the default values of the Sim-RenalGFR_30-60 and RenalGFR_less_30 populations, respectively. For both samidorphan and olanzapine, it was assumed that the main binding protein was albumin [11]. Albumin levels for subjects with normal RF and with mild, moderate, and severe RI are shown in Table 2.

Non-renal clearance of drugs consists largely of hepatic metabolism mediated by CYP and UGT enzymes. Although hepatic enzyme expression data in subjects with RI are not available, abundance values have been extrapolated using clinical data from patients with mild, moderate, or severe RI (Table 2) [19, 31]. The default values in the Simcyp Simulator for CYP1A2, CYP2C8, and CYP3A4 in the moderate and severe RI populations were applied in all simulations. Sayama and colleagues analyzed data for 151 drugs in subjects with moderate and severe RI to derive scalars for changes in non-renal clearance via CYP and UGT-mediated metabolism and via other undisclosed mechanisms [31]. Median scalars of 0.68 and 0.65 were reported for changes in CYP-mediated hepatic metabolism for patients with moderate and severe RI relative to healthy subjects, respectively. Corresponding values of 0.67 and 0.59 were reported for median changes in UGT metabolism. These latter values were applied to hepatic UGT1A4 abundance values of 52 $\mathrm{pmol} / \mathrm{mg}$ protein in healthy subjects to obtain estimates of 34.8 and $30.7 \mathrm{pmol} / \mathrm{mg}$ protein in moderate and severe RI, respectively. The CYP3A4 abundances for a population with mild RI based on extrapolation from clinical data (nifedipine, rivaroxaban, reboxetine, tolvaptan, tadalafil, and eplenerone) were estimated to be $120.9 \mathrm{pmol} / \mathrm{mg}$ protein $(0.88$ of the baseline value in healthy subjects). Thus, this scalar was applied to obtain estimates of CYP1A2, CYP2C8, and UGT1 A4 abundances in subjects with mild RI. The changes in enzyme abundance levels and in other parameters that were used in the simulations of subjects with RI are shown in Table 2.

\subsection{Model Validation}

The PBPK model for OLZ/SAM was previously validated by comparing simulated plasma $C-T$ profiles and pharmacokinetic parameters of olanzapine and samidorphan with observed clinical data following a single dose of OLZ/ SAM $10 \mathrm{mg} / 10 \mathrm{mg}$ (10/10) in healthy subjects [14, 32], and 
Fig. 2 Physiologically based pharmacokinetic (PBPK) models for olanzapine (a) and samidorphan (b) [22]. The PBPK models selected for olanzapine and samidorphan described the disposition of each drug with reasonable accuracy when compared with clinical data.

The minimal PBPK model for olanzapine considers both liver and intestinal metabolism, while other tissues are considered as a single adjusting compartment. The model for samidorphan includes discrete compartments for additional tissues such as adipose, brain, bone, heart, lung, muscle, and skin a

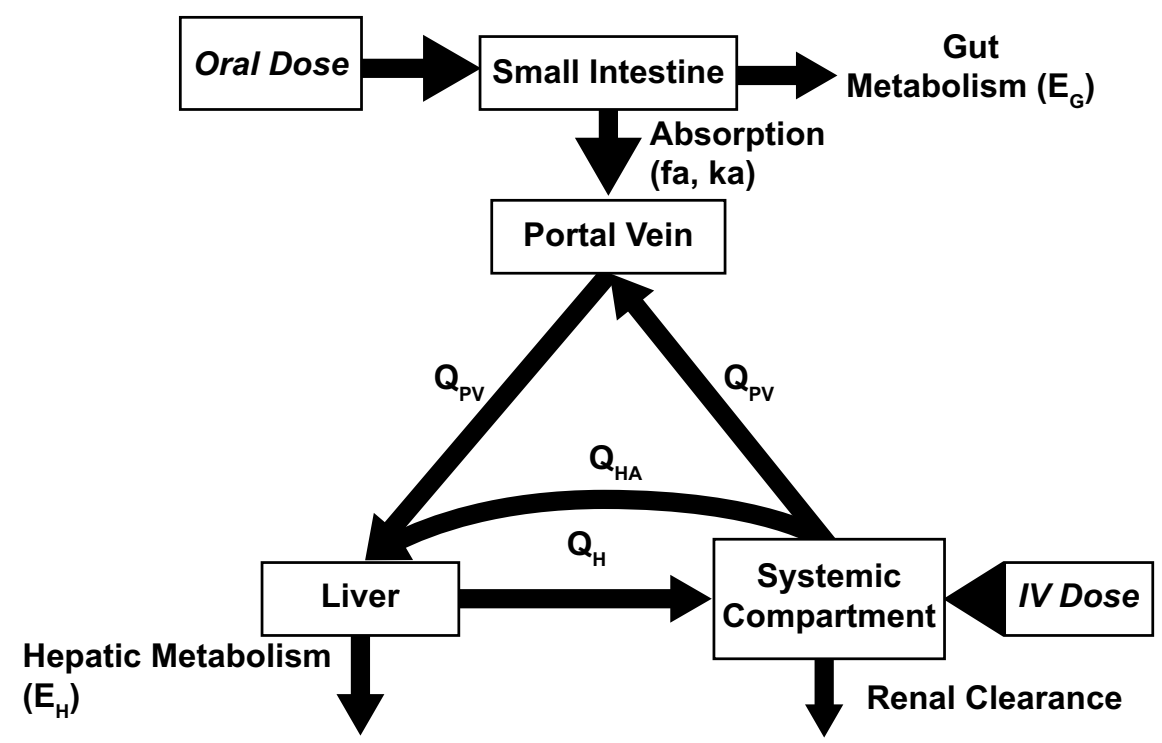

b

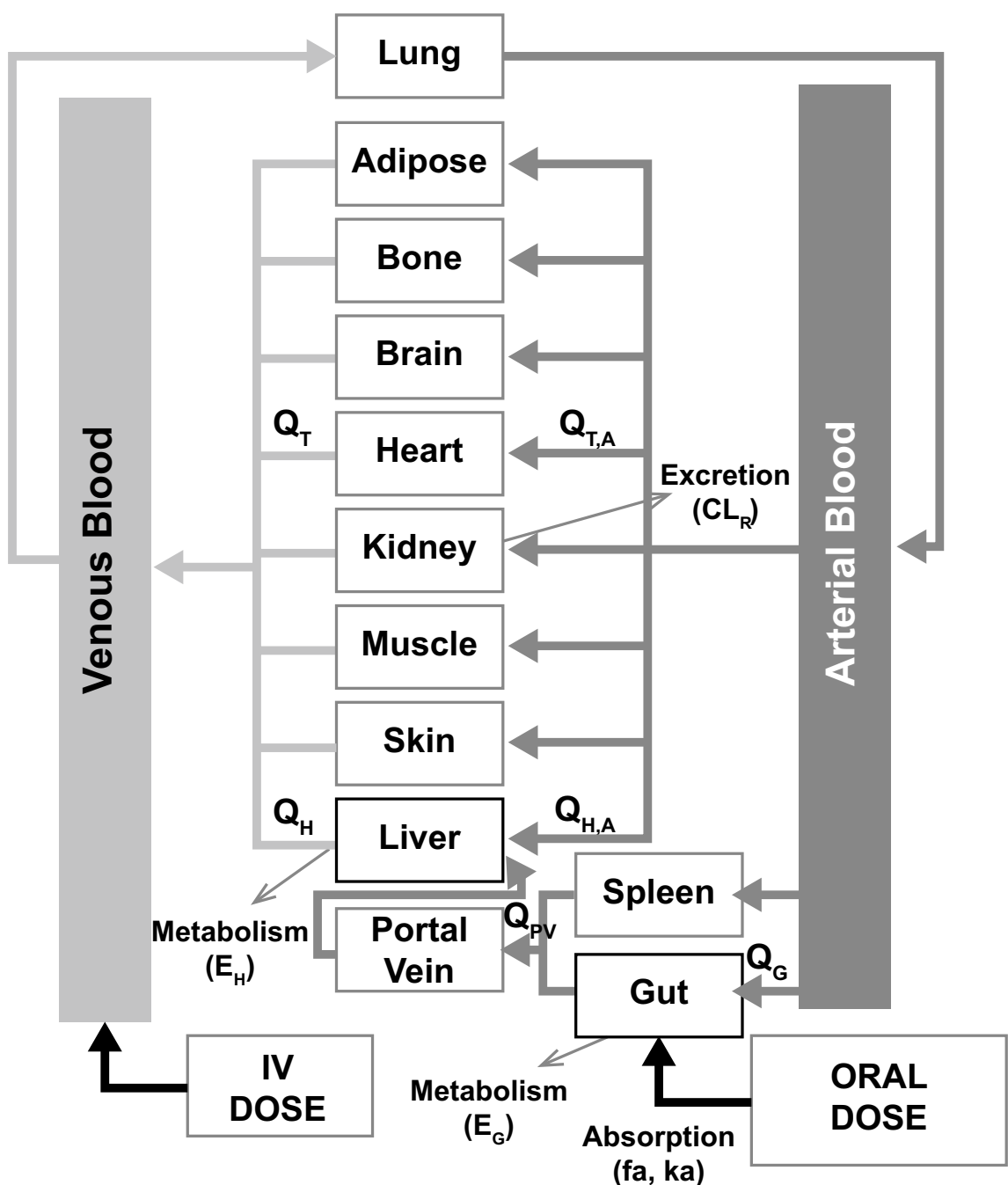


Table 1 Input parameter values [22]

\begin{tabular}{|c|c|c|}
\hline Parameter & & Source/references \\
\hline \multicolumn{3}{|l|}{ Olanzapine } \\
\hline Molecular weight & 312.43 & www.drugbank.ca/drugs/DB00334\#admet \\
\hline $\log P$ & 2.89 & El Ela et al. [23] \\
\hline Compound type & Monoprotic base & Callaghan et al. [11] \\
\hline $\mathrm{pKa} 1$ & 7.24 & Callaghan et al. [11] \\
\hline $\mathrm{B}: \mathrm{P}$ & 0.62 & Callaghan et al. [11] \\
\hline fu & 0.07 & Kassahun et al. [15] \\
\hline$V_{\mathrm{ss}}(\mathrm{L} / \mathrm{kg})$ & 5.0 & Optimized $^{\mathrm{a}}$ \\
\hline Сaco-2 Papp $\mathrm{A-B} 7.4: 7.4\left(10^{-6} \mathrm{~cm} / \mathrm{s}\right)$ & 17.37 & \multirow[t]{2}{*}{ Unpublished data (Alkermes, Inc.) } \\
\hline Calibrator: atenolol & 0.146 & \\
\hline$P_{\text {eff,man }}\left(10^{-4} \mathrm{~cm} / \mathrm{s}\right)$ & 3.84 & Predicted from Caco-2 data \\
\hline$Q_{\mathrm{Gut}}(\mathrm{L} / \mathrm{h})$ & 13.8 & Predicted from Caco- 2 data \\
\hline fa & 1.0 & Predicted from Caco- 2 data \\
\hline $\mathrm{ka}\left(\mathrm{h}^{-1}\right)$ & 0.6 & Optimized \\
\hline $\mathrm{CL}_{\mathrm{int}, \mathrm{u}}(\mu \mathrm{L} / \mathrm{min} / \mathrm{mg})$ & 57.93 & Retrograde approach using $\mathrm{CL}_{\mathrm{PO}}$ from Callaghan et al. [11] \\
\hline CYP1A2 & 23.67 & \multirow{5}{*}{$\begin{array}{l}\text { Enzyme contribution based on recombinant data and chemical } \\
\text { inhibition data in human liver microsomes; Korprasertthaworn } \\
\text { et al. [24] }\end{array}$} \\
\hline CYP2C8 & 4.98 & \\
\hline CYP3A4 & 4.42 & \\
\hline UGT1A4 & 20.58 & \\
\hline FM03 & 4.28 & \\
\hline $\mathrm{CL}_{\mathrm{R}}(\mathrm{L} / \mathrm{h})$ & 0.81 & Kassahun et al. [15] \\
\hline \multicolumn{3}{|l|}{ Samidorphan } \\
\hline Molecular weight & 370.44 & Unpublished data (Alkermes, Inc.) \\
\hline $\log P$ & 2.4 & Unpublished data (Alkermes, Inc.) \\
\hline Compound type & Ampholyte & Unpublished data (Alkermes, Inc.) \\
\hline pKa1 (acid), pKa2 (base) & $7.5 ; 8.2$ & Unpublished data (Alkermes, Inc.) \\
\hline $\mathrm{B}: \mathrm{P}$ & 1 & Unpublished data (Alkermes, Inc.) \\
\hline fu & 0.69 & Unpublished data (Alkermes, Inc.) \\
\hline$V_{\mathrm{ss}}(\mathrm{L} / \mathrm{kg})$ & 3.43 & Predicted (Rodgers and Rowland, 2006) [25] \\
\hline Саco-2 Papp $\mathrm{A-B} 6.5: 7.4\left(10^{-6} \mathrm{~cm} / \mathrm{s}\right)$ & 18.77 & Unpublished data (Alkermes, Inc.) \\
\hline Calibrator: atenolol & 0.121 & \\
\hline$P_{\text {eff,man }}\left(10^{-4} \mathrm{~cm} / \mathrm{s}\right)$ & 4.60 & Predicted from Caco-2 data \\
\hline$Q_{\text {Gut }}(\mathrm{L} / \mathrm{h})$ & 14.8 & Predicted from Caco- 2 data \\
\hline $\mathrm{fa}$ & 1.0 & Predicted from Caco- 2 data \\
\hline \multirow[t]{2}{*}{$\mathrm{ka}\left(\mathrm{h}^{-1}\right)$} & 2.01 & Predicted from Caco-2 data \\
\hline & 0.7 & Optimized \\
\hline $\mathrm{CL}_{\mathrm{int}, \mathrm{u}}(\mu \mathrm{L} / \mathrm{min} / \mathrm{mg}$ protein $)$ & 11.15 & Unpublished data (Alkermes, Inc.) \\
\hline CYP3A4 & 5.93 & Unpublished data (Alkermes, Inc.) \\
\hline Non-CYP3A4 & 5.22 & \\
\hline $\mathrm{CL}_{\mathrm{R}}(\mathrm{L} / \mathrm{h})$ & 11 & Unpublished data (Alkermes, Inc.) \\
\hline$K_{\mathrm{i}, \mathrm{u}}(\mu \mathrm{M}):$ CYP2D6 & 41.5 & Unpublished data (Alkermes, Inc.) \\
\hline $\mathrm{fu}_{\mathrm{mic}}$ at $0.5 \mathrm{mg} / \mathrm{mL}$ & 0.86 & \\
\hline
\end{tabular}

Parameters in bold were used as direct inputs to Simcyp

$B: P$ blood-to-plasma partition ratio, $C L_{\text {int, }}$ unbound intrinsic metabolic clearance, $C L_{P O}$ oral clearance, $C L_{R}$ renal plasma clearance, $C Y P$ cytochrome P450 enzyme, $f a$ fraction absorbed from the gut, $F M O 3$ flavin-containing monooxygenase 3 , $f u$ fraction unbound in plasma, $f u_{m i c}$ fraction of unbound substrate or inhibitor in a microsomal incubation, $k a$ first-order absorption rate constant, $K_{i, u}$ enzyme competitive inhibition constant corrected for the fraction of unbound drug, $P_{a p p_{A B}}$ apparent absorption permeability, $P_{\text {eff.man }}$ in vivo permeability, $p K a$ negative base-10 logarithm of the acid dissociation constant $(\mathrm{Ka})$ of a solution (i.e., $\mathrm{pKa}=-\log _{10} \mathrm{Ka}$ ), $Q_{G u t}$ nominal blood flow in the gut, $U G T$ uridine diphosphoglucuronosyltransferase, $V_{s s}$ volume of distribution at steady state

${ }^{a}$ Based on Rodgers and Rowland (2006) [25] and Poulin and Thiel (2002) [26] 
Table 2 System parameters for subjects with normal renal function, mild RI, moderate RI, and severe RI

\begin{tabular}{lcccc}
\hline Parameter & Healthy & Mild RI & Moderate RI & Severe RI \\
\hline Abundance (pmol/mg protein) & & & & \\
CYP3A4 & 137 & 120.9 & 95.2 & 87.3 \\
CYP1A2 & 54.0 & 47.7 & 28.4 & 27.4 \\
CYP2C8 & 24.0 & 21.2 & 13.1 & 11.3 \\
UGT1A4 & 52.0 & 45.9 & 34.8 & 30.7 \\
Albumin (g/L) & & & & 37.0 \\
Male & 45.2 & 45.2 & 41.0 & 31.2 \\
Female & 43.1 & 43.1 & 39.8 & 33.2 \\
Hematocrit (\%) & & & 31.3 \\
Male & 43.0 & 39.7 & 39.7 & 20.6 \\
Female & 38.0 & 36.5 & 36.5 & 42.0 \\
Creatinine clearance (mL/min) & 94.7 & 67.8 & 42.0 \\
\hline
\end{tabular}

CYP cytochrome $\mathrm{P} 450$ enzyme, $R I$ renal impairment, $U G T$ uridine diphosphoglucuronosyltransferase following multiple once-daily doses of OLZ/SAM 10/10 for 14 days in patients with schizophrenia [13]. Additional model validation was conducted by comparing modelsimulated $C-T$ profiles and pharmacokinetic parameters of olanzapine and samidorphan, including the $C_{\max }$, AUC, and apparent clearance, with observed data from the clinical study evaluating the impact of severe RI on the pharmacokinetics of olanzapine and samidorphan [16]. Virtual trials were generated to match subject demographics (i.e., age and sex) and treatment characteristics of the clinical study [16]: ten trials of ten subjects with severe RI ( $30 \%$ female; aged 38-72 years) receiving a single dose of OLZ/SAM 5/10, and ten trials of ten healthy controls with normal renal function (30\% female; aged 59-73 years) receiving a single dose of OLZ/SAM 5/10. Simulated values for healthy subjects, with the exception of demographic data, were derived from a Caucasian population using default Simcyp parameter values.

\subsection{Model Application}

The validated model was applied to predict changes in steady-state systemic exposures of olanzapine and samidorphan after multiple once-daily administration of OLZ/SAM 10/10. Each simulation consisted of ten virtual trials of ten subjects each (30\% female; aged 38-72 years) in the following groups: (1) subjects with mild RI; (2) subjects with moderate RI; (3) subjects with severe RI; and (4) healthy control subjects with normal renal function, based on the following definitions of renal function: normal (estimated glomerular filtration rate [eGFR] of $\geq 90 \mathrm{~mL} / \mathrm{min} / 1.73 \mathrm{~m}^{2}$ ), mild RI (eGFR of $\geq 60$ to $<90 \mathrm{~mL} / \mathrm{min} / 1.73 \mathrm{~m}^{2}$ ), moderate RI (eGFR of $\geq 30$ to $<60 \mathrm{~mL} / \mathrm{min} / 1.73 \mathrm{~m}^{2}$ ), and severe RI (eGFR of $\geq 15$ to $<30 \mathrm{~mL} / \mathrm{min} / 1.73 \mathrm{~m}^{2}$ ).

\section{Results}

\subsection{Model Validation}

Model-simulated mean plasma $C-T$ profiles and pharmacokinetic parameters of olanzapine and samidorphan in subjects with severe RI and healthy controls after a single dose of OLZ/SAM 5/10 were consistent with observed data [16] (Fig. 3; Table 3). A high intersubject variability in the pharmacokinetic profiles of olanzapine and samidorphan was noted in subjects with RI (Fig. 3a, c) compared with the healthy controls (Fig. 3b, d). This is likely caused by alterations in drug bioavailability and clearance owing to chronic renal disease and/or potential pharmacokinetic interactions with concomitant medications received by subjects with renal impairment [16]. The effects of severe RI on the pharmacokinetics of olanzapine and samidorphan observed in the clinical study [16] were well predicted (Table 4). Based on geometric mean data, the model predicted a 1.5fold increase in the total exposure $\left(\mathrm{AUC}_{0-\infty}\right)$ of olanzapine in subjects with severe RI compared with healthy controls, which was consistent with the 1.5-fold increase observed in the clinical study [16]. Similarly, the model predicted a 2.2fold increase in the $\mathrm{AUC}_{0-\infty}$ of samidorphan in subjects with severe RI, consistent with the 2.3-fold increase observed in the clinical study [16]. Model-predicted reductions of 38\% and 54\% in olanzapine and samidorphan total clearance, respectively, in subjects with severe RI, were also consistent with the reductions of $33 \%$ and $56 \%$, respectively, observed in the clinical study [16].

\subsection{Model Application}

Simulated steady-state plasma $C-T$ profiles of olanzapine and samidorphan in subjects with mild, moderate, or severe 
RI compared with healthy, age-matched control subjects after once-daily administration of OLZ/SAM 10/10 for 14 days are depicted in Fig. 4a, b. Model-predicted steadystate maximum plasma concentration $\left(C_{\text {max,ss }}\right)$ and area under the $C-T$ curve over the 24-hour dosing interval (AUC $\tau, \mathrm{ss})$ of olanzapine and samidorphan in subjects with mild, moderate, or severe RI compared with healthy controls are presented in Table 5. Physiologically based pharmacokinetic predictions indicated that $C_{\text {max,ss }}$ and $\mathrm{AUC}_{\tau, \mathrm{ss}}$ of olanzapine and samidorphan increased consistently as the severity of RI increased. Compared with subjects with normal renal function, an increase in $\mathrm{AUC}_{\tau, \mathrm{ss}}$ was predicted to be $<1.5$-fold for both olanzapine and samidorphan in subjects with mild RI, 1.5-fold for olanzapine, and 1.8-fold for samidorphan in subjects with moderate RI, and 1.6-fold for olanzapine and 2.2-fold for samidorphan in subjects with severe RI. The increase in $C_{\text {max,ss }}$ was predicted to be up to 1.5 -fold higher for both olanzapine and samidorphan in subjects with severe RI. a

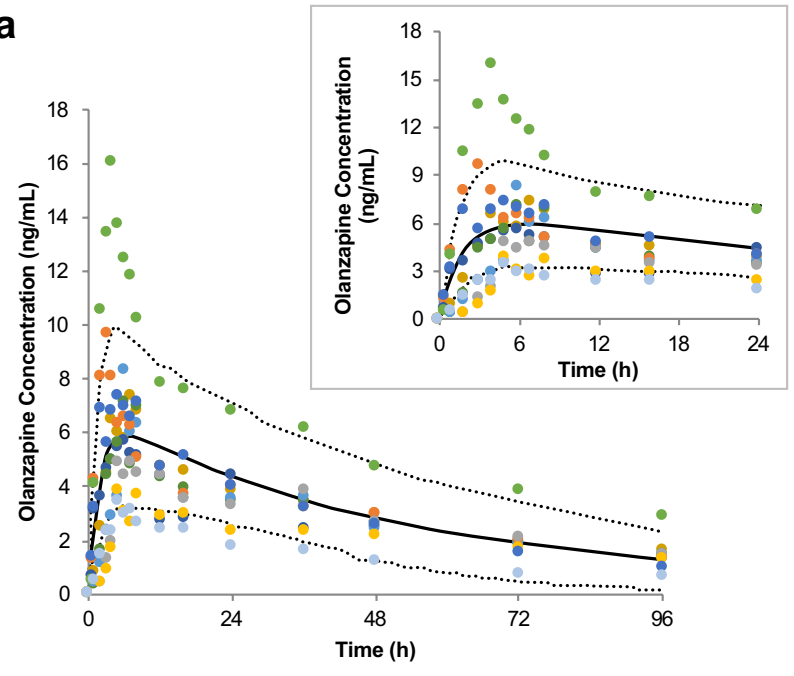

C

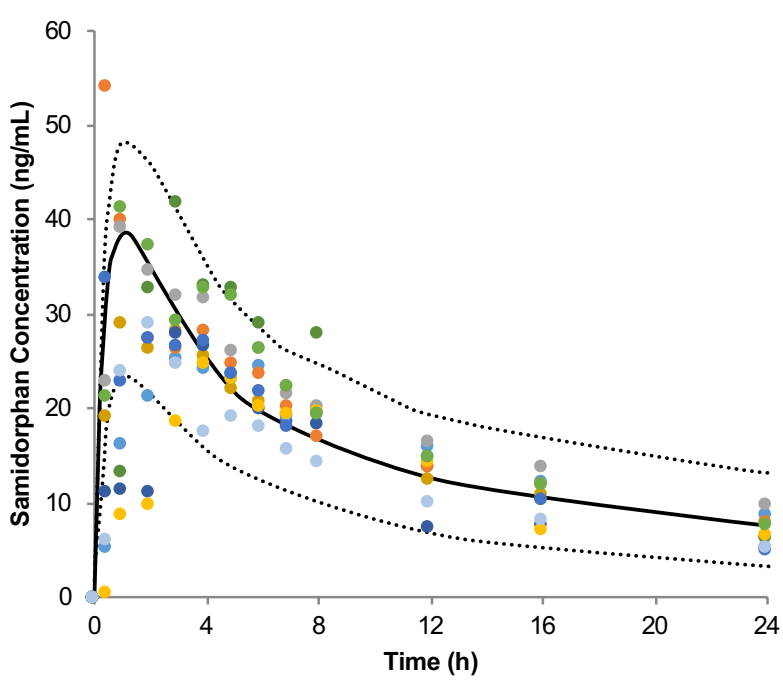

Fig. 3 Observed and simulated concentrations of olanzapine and samidorphan after a single dose of the combination of olanzapine and samidorphan (OLZ/SAM) $5 \mathrm{mg} / 10 \mathrm{mg}$ in subjects with severe renal impairment (RI) and in healthy controls (model validation). Observed and simulated concentrations of olanzapine in a subjects with severe renal impairment and $\mathbf{b}$ healthy controls, and of samidorphan in $\mathbf{c}$ subjects with severe renal impairment and $\mathbf{d}$ healthy controls. Insets b
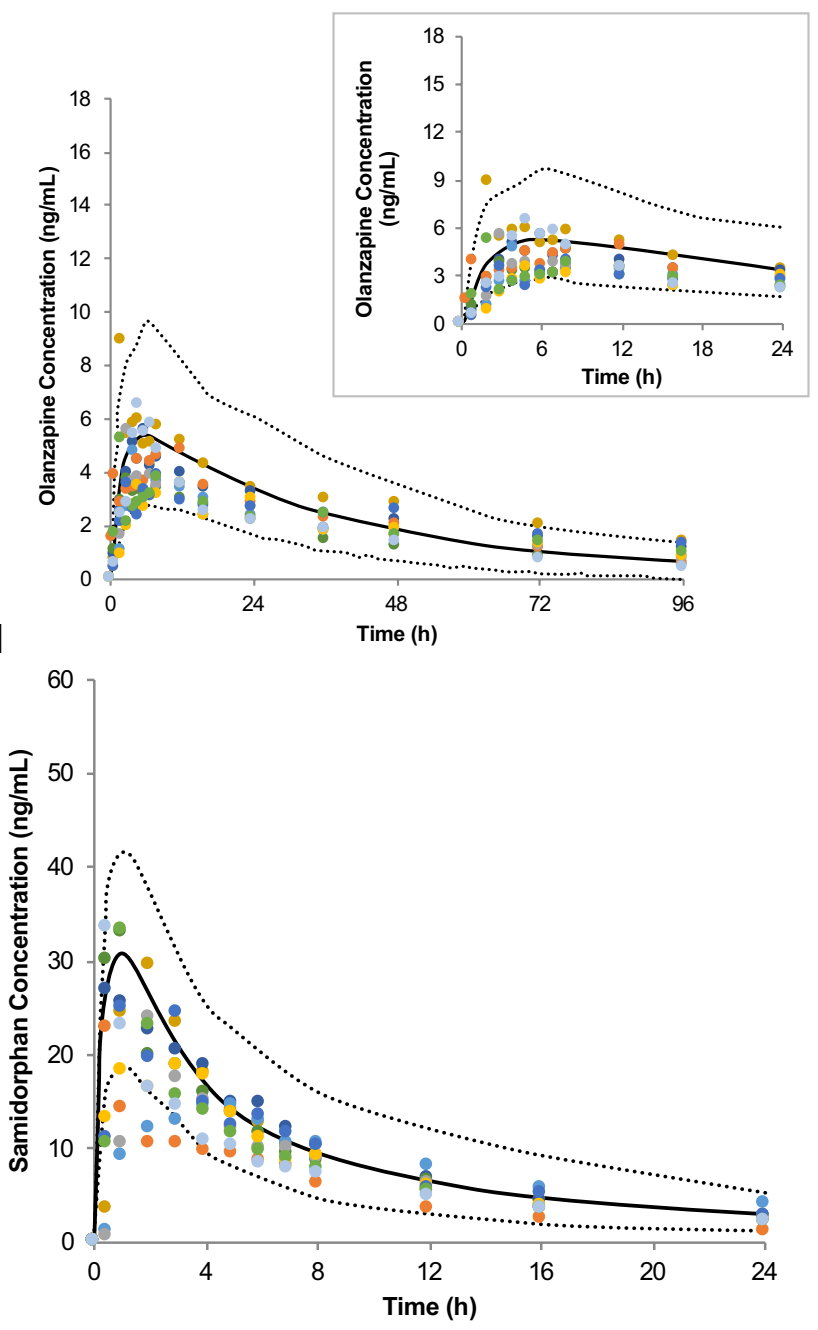

in $\mathbf{a}$ and $\mathbf{b}$ depict olanzapine concentrations from 0 to $24 \mathrm{~h}$, as data points are densely clustered during that time period. The solid line represents the mean for the simulated population $(n=100)$, and the dashed lines are the 5th and 95th percentiles of the population. The round symbols represent observed individual data from the clinical study [16]; each patient $(n=10)$ is indicated by a distinct color 
Table 3 Comparison of model-predicted and observed arithmetic mean $C_{\max }$, AUC, and $t_{1 / 2}$ values for olanzapine or samidorphan after a single dose of OLZ/SAM in subjects with severe RI and healthy control subjects with normal renal function (model validation)

\begin{tabular}{|c|c|c|c|c|c|c|}
\hline & \multicolumn{3}{|l|}{ Olanzapine } & \multicolumn{3}{|l|}{ Samidorphan } \\
\hline & $C_{\max }(\mathrm{ng} / \mathrm{mL})$ & AUC (ng.h/mL) & $t^{1} / 2(\mathrm{~h})$ & $C_{\max }(\mathrm{ng} / \mathrm{mL})$ & AUC (ng.h/mL) & $t^{1 / 2}(\mathrm{~h})$ \\
\hline \multicolumn{7}{|c|}{ Single dose of OLZ/SAM $5 \mathrm{mg} / 10 \mathrm{mg}$ in subjects with severe RI } \\
\hline Simulated (trial range) $[n=100]$ & $5.96(4.35-7.37)$ & $400(319-515)$ & $45.0(34.2-53.3)$ & $38.8(35.0-43.3)$ & $619(527-751)$ & $20.8(18.9-23.0)$ \\
\hline Observed [16] (range) $[n=10]$ & $7.36(3.5-16.0)$ & $404(170-729)$ & $57.8(39.1-92.4)$ & $34.6(24.6-54.2)$ & $530(353-691)$ & $17.1(9.9-23.8)$ \\
\hline Ratio of simulated/observed & 0.8 & 1.0 & 0.8 & 1.1 & 1.2 & 1.2 \\
\hline \multicolumn{7}{|c|}{ Single dose of OLZ/SAM $5 \mathrm{mg} / 10 \mathrm{mg}$ in healthy controls with normal renal function } \\
\hline Simulated (trial range) $(n=100)$ & $5.35(4.27-6.44)$ & $252(193-312)$ & $30.0(27.6-36.4)$ & $31.2(27.3-34.7)$ & $285(239-344)$ & $13.2(12.4-13.7)$ \\
\hline Observed [16] (range) $(n=10)$ & $5.25(3.5-8.9)$ & $256(177-391)$ & $45.6(31.7-68.3)$ & $26.1(14.4-33.5)$ & $233(143-298)$ & $11.4(7.8-18.2)$ \\
\hline Ratio of simulated/observed & 1.0 & 1.0 & 0.7 & 1.2 & 1.2 & 1.2 \\
\hline
\end{tabular}

$A U C$ area under the concentration-time curve, $C_{\max }$ maximum concentration, OLZ/SAM combination of olanzapine and samidorphan, $R I$ renal impairment, $t_{1 / 2}$ half-life

Table 4 Comparison of model-predicted and observed $\mathrm{C}_{\max }$, AUC, and clearance values for olanzapine and samidorphan after a single dose of OLZ/SAM in subjects with severe RI relative to healthy control subjects with normal renal function (model validation)

\begin{tabular}{|c|c|c|c|c|c|c|c|c|c|}
\hline \multirow[t]{2}{*}{ Parameter } & \multicolumn{3}{|c|}{$C_{\max }^{\mathrm{a}}(\mathrm{ng} / \mathrm{mL})$} & \multicolumn{3}{|c|}{$\mathrm{AUC}^{\mathrm{a}}(\mathrm{ng} \cdot \mathrm{h} / \mathrm{mL})$} & \multicolumn{3}{|c|}{$\mathrm{CL} / \mathrm{F}^{\mathrm{b}}(\mathrm{L} / \mathrm{h})$} \\
\hline & $\begin{array}{l}\text { Age- } \\
\text { matched } \\
\text { control }\end{array}$ & Severe RI & Ratio $^{c}$ & $\begin{array}{l}\text { Age- } \\
\text { matched } \\
\text { control }\end{array}$ & Severe RI & Ratio $^{c}$ & $\begin{array}{l}\text { Age- } \\
\text { matched } \\
\text { control }\end{array}$ & Severe RI & Ratio $^{\mathrm{c}}$ \\
\hline Olanzapine, observed $(n=10)[16]$ & 5.07 & 6.71 & 1.3 & 268 & 403 & 1.5 & 20.7 & 13.9 & 0.67 \\
\hline Olanzapine, simulated $(n=100)$ & 4.99 & 5.62 & 1.1 & 221 & 327 & 1.5 & 23.5 & 14.6 & 0.62 \\
\hline Samidorphan, observed $(n=10)[16]$ & 25.2 & 34.5 & 1.4 & 234 & 540 & 2.3 & 44.6 & 19.7 & 0.44 \\
\hline Samidorphan, simulated $(n=100)$ & 30.2 & 37.9 & 1.3 & 267 & 576 & 2.2 & 40.2 & 18.4 & 0.46 \\
\hline
\end{tabular}

$A U C$ area under the plasma drug concentration-time curve, $C L / F$ apparent total clearance, $C_{\max }$ maximum plasma concentration, $O L Z / S A M$ combination of olanzapine and samidorphan, $R I$ renal impairment

${ }^{\mathrm{a}}$ Geometric mean

${ }^{\mathrm{b}}$ Arithmetic mean

${ }^{\mathrm{c}}$ Severe RI relative to age-matched controls with normal renal function

\section{Discussion}

A PBPK model for OLZ/SAM was developed and validated using observed data obtained from multiple clinical studies with OLZ/SAM [13, 14, 32]. The model-simulated exposures for both olanzapine and samidorphan were within $25 \%$ of observed data in healthy subjects following a single dose of OLZ/SAM 10/10 [14, 32]. The model also well predicted the observed plasma exposure ( $C_{\max }$ and AUC) of olanzapine (within 10\%) and samidorphan (within 50\%) following multiple-dose administration of OLZ/SAM $10 / 10$ or 20/10 in patients with schizophrenia [13].

The PBPK model for OLZ/SAM was further validated using observed data obtained from the clinical study evaluating the impact of severe RI on the pharmacokinetics of olanzapine and samidorphan [16]. The predicted increases in olanzapine and samidorphan $\mathrm{AUC}_{0-\infty}$ (1.5- and 2.2-fold, respectively) in subjects with severe RI relative to healthy age-matched subjects with normal renal function corresponded with decreases in their respective total clearance (38\% and 54\%). These predictions are in alignment with the 1.5- and 2.3-fold increases in $\mathrm{AUC}_{0-\infty}$ and $33 \%$ and $56 \%$ decreases in total clearance of olanzapine and samidorphan, respectively, observed in the clinical study [16]. The greater effect of severe RI on samidorphan exposure and clearance than on that of olanzapine is likely because the extent of renal excretion is greater for samidorphan than for olanzapine (20\% vs $7 \%$, respectively $[15,16])$.

Application of the validated PBPK model for the prediction of the effect of mild, moderate, and severe RI on the steady-state exposures of olanzapine and samidorphan following multiple doses of OLZ/SAM indicated that the impact of RI on the pharmacokinetics of olanzapine and samidorphan increased with increasing severity of RI. Mild RI was predicted to have a minimal impact on olanzapine 
Fig. 4 Simulated mean plasma concentrations of olanzapine (a) and samidorphan (b) after oncedaily doses of the combination of olanzapine and samidorphan (OLZ/SAM) $10 \mathrm{mg} / 10 \mathrm{mg}$ for 14 days (model application). The lines represent the mean for the simulated populations $(n=100)$ of healthy controls with normal renal function (black) and subjects with mild renal impairment [RI[ (green), moderate RI (blue), and severe RI (red)
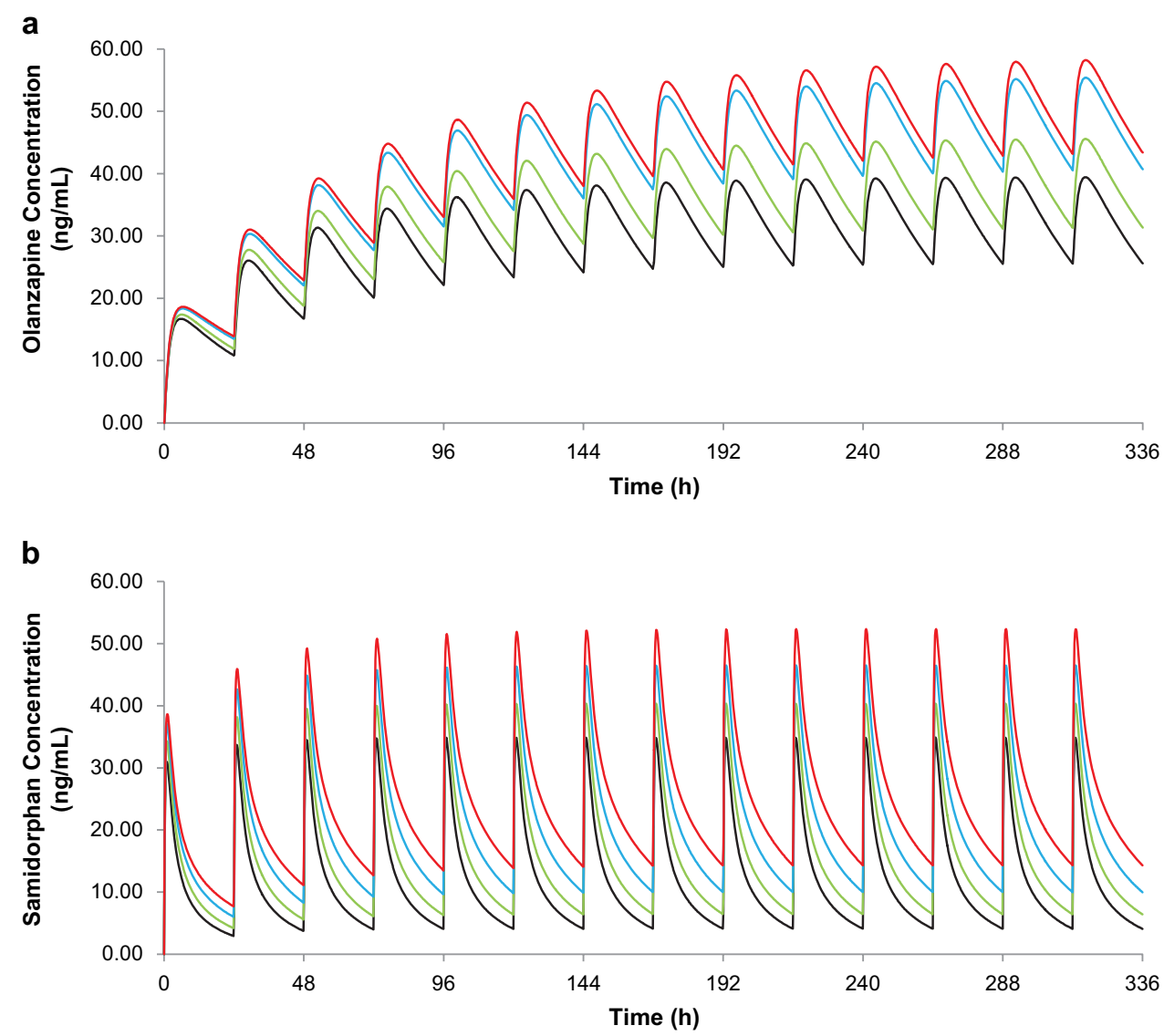

Table 5 Model-predicted steady-state $C_{\max }$ and AUC values for olanzapine and samidorphan after once-daily doses of OLZ/SAM $10 \mathrm{mg} / 10 \mathrm{mg}$ for 14 days in subjects with RI compared with age-matched healthy controls (model application)

\begin{tabular}{|c|c|c|c|c|c|c|c|c|}
\hline \multirow[t]{2}{*}{ Parameter } & \multicolumn{4}{|l|}{$C_{\max }{ }^{\mathrm{a}}(\mathrm{ng} / \mathrm{mL})$} & \multicolumn{4}{|c|}{$\mathrm{AUC}^{\mathrm{a}}(\mathrm{ng} \cdot \mathrm{h} / \mathrm{mL})$} \\
\hline & $\begin{array}{l}\text { Age-matched } \\
\text { control }\end{array}$ & Mild RI & Moderate RI & Severe RI & $\begin{array}{l}\text { Age-matched } \\
\text { control }\end{array}$ & Mild RI & Moderate RI & Severe RI \\
\hline Olanzapine & 37.0 & 42.8 & 52.7 & 55.4 & 738 & 868 & 1104 & 1166 \\
\hline Ratio $^{\mathrm{b}}$ & - & 1.2 & 1.4 & 1.5 & - & 1.2 & 1.5 & 1.6 \\
\hline Samidorphan & 33.8 & 40.8 & 45.3 & 50.8 & 267 & 367 & 467 & 582 \\
\hline Ratio $^{b}$ & - & 1.2 & 1.3 & 1.5 & - & 1.4 & 1.8 & 2.2 \\
\hline
\end{tabular}

$A U C$ area under the plasma drug concentration-time curve, $C_{\max }$ maximum plasma concentration, $O L Z / S A M$ combination of olanzapine and samidorphan, $R I$ renal impairment

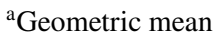

${ }^{\mathrm{b}}$ Relative to age-matched controls with normal renal function

and samidorphan exposures, with $<1.5$-fold increases in $C_{\text {max,ss }}$ and $\mathrm{AUC}_{\tau, \mathrm{ss}}$, whereas moderate-to-severe RI resulted in up to 1.5 -fold increases in $C_{\text {max,ss }}$ and up to a 2.2-fold increase in $\mathrm{AUC}_{\tau, \mathrm{ss}}$ of olanzapine and samidorphan relative to subjects with normal renal function.

Although increases in fu with increasing severity of RI were initially predicted for olanzapine $(0.071-0.088)$ and samidorphan (0.69-0.74), data from the clinical study indicated that the fu value for olanzapine was similar in subjects with severe RI and in healthy controls with normal renal function [16]. Therefore, in the current modeling predictions, the fu value was fixed for both olanzapine and samidorphan and was assumed to be the same in healthy subjects and across all categories of RI, which allowed improved recovery of the observed change in exposure for both olanzapine and samidorphan in subjects with severe RI. 
Whereas model simulations provided predictions of the impact of varying degrees of RI on the pharmacokinetics of olanzapine and samidorphan after OLZ/SAM administration, model validation was based on comparison with observed clinical data in subjects without psychiatric illness who had severe RI or normal renal function. Patients with schizophrenia or bipolar I disorder (indications for which OLZ/SAM is in development) were not specifically assessed. However, the OLZ/SAM PBPK model was able to predict the observed clinical pharmacokinetic data well in patients with schizophrenia who were administered multiple doses of OLZ/SAM [13]. A majority of the patients with schizophrenia were smokers, and smoking is associated with an increase in CYP1A2 abundance [22]. Because olanzapine exposure is known to be lower in smokers compared with nonsmokers, and samidorphan exposure is not affected by smoking [22], the effect of RI evaluated based on nonsmokers is a more conservative estimate of the higher drug exposure levels due to RI. Although many people with CKD also have other comorbidities, such as diabetes mellitus or high blood pressure, the impact of comorbidities associated with RI on the pharmacokinetics of olanzapine and samidorphan was not assessed. Use of controls without psychiatric disease avoids confounding that may occur because of those disease states (e.g., physical comorbidities such as diabetes, which may involve kidney damage, could obscure meaningful conclusions) [17, 18, 33].

In a previous thorough QT study, multiple-dose administration of a high dose of OLZ/SAM $(30 \mathrm{mg} / 30 \mathrm{mg} ; 1.5$ and three times the maximum recommended daily dose of olanzapine and samidorphan, respectively) was well tolerated in patients with schizophrenia [34]. As such, the anticipated therapeutic doses of OLZ/SAM (10/10 to 20/10) would be expected to be well tolerated should the systemic exposures of olanzapine and samidorphan be elevated in patients with severe RI [16]. However, to minimize the potential risk of modest increases in olanzapine and samidorphan exposures in patients with moderate or severe RI, the lowest dose of OLZ/SAM that achieves an adequate clinical response should be used.

In conclusion, PBPK modeling predictions indicated a minimal effect of mild RI on the pharmacokinetics of olanzapine and samidorphan, whereas moderate-to-severe RI was predicted to result in moderate increases in steady-state exposures of olanzapine (up to 1.6-fold) and samidorphan (up to 2.2-fold). In lieu of dedicated clinical studies, PBPK modeling allows for extending available clinical data to additional subgroups, especially in populations where conducting trials can be challenging (e.g., subjects with RI). Ultimately, this may reduce the number of patients needed to characterize new pharmacologic entities, and may be associated with investigational time and cost savings.
Acknowledgements The authors thank Mark S. Todtenkopf, Ph.D., who assisted in the preparation and proofreading of the manuscript. Medical writing and editorial support was provided by Gina Daniel, Ph.D., and John H. Simmons, MD, of Peloton Advantage, LLC, an OPEN Health company, and funded by Alkermes, Inc.

\section{Declarations}

Funding This study was sponsored by Alkermes, Inc.

Conflict of Interest Lei Sun is an employee of Alkermes, Inc. Lisa von Moltke was an employee of Alkermes, Inc. at the time of the study. Karen Rowland Yeo is an employee of Certara UK Limited, Simcyp Division.

Ethics Approval The initial clinical study [16] was conducted in accordance with the principles of the Declaration of Helsinki, the International Conference on Harmonisation Good Clinical Practice guidelines, and local regulatory requirements. The study protocol was approved by the institutional review board or independent ethics committee at each study site.

Consent to Participate All subjects provided written informed consent prior to study participation.

Availability of Data and Material The data collected in this study are proprietary to Alkermes, Inc. Alkermes, Inc. is committed to public sharing of data in accordance with applicable regulations and laws.

Open Access This article is licensed under a Creative Commons Attribution-NonCommercial 4.0 International License, which permits any non-commercial use, sharing, adaptation, distribution and reproduction in any medium or format, as long as you give appropriate credit to the original author(s) and the source, provide a link to the Creative Commons licence, and indicate if changes were made. The images or other third party material in this article are included in the article's Creative Commons licence, unless indicated otherwise in a credit line to the material. If material is not included in the article's Creative Commons licence and your intended use is not permitted by statutory regulation or exceeds the permitted use, you will need to obtain permission directly from the copyright holder. To view a copy of this licence, visit http://creativecommons.org/licenses/by-nc/4.0/.

\section{References}

1. Wentland MP, Lou R, Lu Q, et al. Syntheses of novel high affinity ligands for opioid receptors. Bioorg Med Chem Lett. 2009;19:2289-94.

2. Bidlack JM, Knapp BI, Deaver DR, et al. In vitro pharmacological characterization of buprenorphine, samidorphan, and combinations being developed as an adjunctive treatment of major depressive disorder. J Pharmacol Exp Ther. 2018;367:267-81.

3. Shram MJ, Silverman B, Ehrich E, Sellers EM, Turncliff R. Use of remifentanil in a novel clinical paradigm to characterize onset and duration of opioid blockade by samidorphan, a potent mu-receptor antagonist. J Clin Psychopharmacol. 2015;35:242-9.

4. Komossa $\mathrm{K}$, Rummel-Kluge $\mathrm{C}$, Hunger $\mathrm{H}$, et al. Olanzapine versus other atypical antipsychotics for schizophrenia. Cochrane Database Syst Rev. 2010;17(3):CD006654.

5. Lieberman JA, Stroup TS, McEvoy JP, et al. Effectiveness of antipsychotic drugs in patients with chronic schizophrenia. N Engl J Med. 2005;353:1209-23. 
6. Haro JM, Suarez D, Novick D, Brown J, Usall J, Naber D. Threeyear antipsychotic effectiveness in the outpatient care of schizophrenia: observational versus randomized studies results. Eur Neuropsychopharmacol. 2007; 17:235-44.

7. Leucht S, Cipriani A, Spineli L, et al. Comparative efficacy and tolerability of 15 antipsychotic drugs in schizophrenia: a multipletreatments meta-analysis. Lancet. 2013;382:951-62.

8. Yildiz A, Nikodem M, Vieta E, Correll CU, Baldessarini RJ. A network meta-analysis on comparative efficacy and all-cause discontinuation of antimanic treatments in acute bipolar mania. Psychol Med. 2015;45:299-317.

9. Cipriani A, Barbui C, Salanti G, et al. Comparative efficacy and acceptability of antimanic drugs in acute mania: a multiple-treatments meta-analysis. Lancet. 2011;378:1306-15.

10. Berkowitz RL, Patel U, Ni Q, Parks JJ, Docherty JP. The impact of the clinical antipsychotic trials of intervention effectiveness (CATIE) on prescribing practices: an analysis of data from a large midwestern state. J Clin Psychiatry. 2012;73:498-503.

11. Callaghan JT, Bergstrom RF, Ptak LR, Beasley CM. Olanzapine. Pharmacokinetic and pharmacodynamic profile. Clin Pharmacokinet. 1999;37:177-93.

12. Turncliff R, DiPetrillo L, Silverman B, Ehrich E. Single- and multiple-dose pharmacokinetics of samidorphan, a novel opioid antagonist, in healthy volunteers. Clin Ther. 2015;37:338-48.

13. Sun L, McDonnell D, von Moltke L. Pharmacokinetics and shortterm safety of ALKS 3831, a fixed-dose combination of olanzapine and samidorphan, in adult subjects with schizophrenia. Clin Ther. 2018;40:1845-54.

14. Sun L, McDonnell D, Liu J, von Moltke L. Bioequivalence of olanzapine given in combination with samidorphan as a bilayer tablet (ALKS 3831) compared with olanzapine-alone tablets: results from a randomized, crossover relative bioavailability study. Clin Pharmacol Drug Dev. 2019a;8:459-66.

15. Kassahun K, Mattiuz E, Nyhart E Jr, et al. Disposition and biotransformation of the antipsychotic agent olanzapine in humans. Drug Metab Dispos. 1997;25:81-93.

16. Sun L, Yagoda S, Du Y, Von Moltke L. Effect of hepatic and renal impairment on the pharmacokinetics of olanzapine and samidorphan given in combination as a bilayer tablet. Drug Des Devel Ther. 2019;13:2941-55.

17. Smith DJ, Martin D, McLean G, Langan J, Guthrie B, Mercer SW. Multimorbidity in bipolar disorder and undertreatment of cardiovascular disease: a cross sectional study. BMC Med. 2013;11:263.

18. Schoepf D, Uppal H, Potluri R, Heun R. Physical comorbidity and its relevance on mortality in schizophrenia: a naturalistic 12-year follow-up in general hospital admissions. Eur Arch Psychiatry Clin Neurosci. 2014;264:3-28.

19. Rowland Yeo K, Aarabi M, Jamei M, Rostami-Hodjegan A. Modeling and predicting drug pharmacokinetics in patients with renal impairment. Expert Rev Clin Pharmacol. 2011;4:261-74.

20. Yuan R, Venitz J. Effect of chronic renal failure on the disposition of highly hepatically metabolized drugs. Int J Clin Pharmacol Ther. 2000;38:245-53.

21. Wagner C, Zhao P, Pan Y, et al. Application of physiologically based pharmacokinetic (PBPK) modeling to support dose selection: report of an FDA public workshop on PBPK. CPT Pharmacomet Syst Pharmacol. 2015;4:226-30.

22. Sun L, von Moltke L, Rowland Yeo K. Physiologically-based pharmacokinetic modeling for predicting drug interactions of a combination of olanzapine and samidorphan. CPT Pharmacomet Syst Pharmacol. 2020;9:106-14.

23. El Ela AA, Hartter S, Schmitt U, Hiemke C, Spahn-Langguth $\mathrm{H}$, Langguth P. Identification of P-glycoprotein substrates and inhibitors among psychoactive compounds: implications for pharmacokinetics of selected substrates. J Pharm Pharmacol. 2004;56:967-75.

24. Korprasertthaworn P, Polasek TM, Sorich MJ, et al. In vitro characterization of the human liver microsomal kinetics and reaction phenotyping of olanzapine metabolism. Drug Metab Dispos. 2015;43:1806-14.

25. Rodgers T, Rowland M. Physiologically based pharmacokinetic modelling 2: predicting the tissue distribution of acids, very weak bases, neutrals and zwitterions. J Pharm Sci. 2006;95:1238-57.

26. Poulin P, Theil FP. Prediction of pharmacokinetics prior to in vivo studies. 1. Mechanism-based prediction of volume of distribution. J Pharm Sci. 2002;91:129-56.

27. Couchoud C, Pozet N, Labeeuw M, Pouteil-Noble C. Screening early renal failure: cut-off values for serum creatinine as an indicator of renal impairment. Kidney Int. 1999;55:1878-84.

28. Hsu CY, Bates DW, Kuperman GJ, Curhan GC. Relationship between hematocrit and renal function in men and women. Kidney Int. 2001;59:725-31.

29. Hsu CY, McCulloch CE, Curhan GC. Epidemiology of anemia associated with chronic renal insufficiency among adults in the United States: results from the Third National Health and Nutrition Examination Survey. J Am Soc Nephrol. 2002;13:504-10.

30. Vanholder R, Van Landschoot N, De Smet R, Schoots A, Ringoir $S$. Drug protein binding in chronic renal failure: evaluation of nine drugs. Kidney Int. 1988;33:996-1004.

31. Sayama H, Takubo H, Komura H, Kogayu M, Iwaki M. Application of a physiologically based pharmacokinetic model informed by a top-down approach for the prediction of pharmacokinetics in chronic kidney disease patients. AAPS J. 2014;16:1018-28.

32. Sun L, McDonnell D, Liu J, von Moltke L. Effect of food on the pharmacokinetics of a combination of olanzapine and samidorphan. Clin Pharmacol Drug Dev. 2019b;8:503-10.

33. Barrett EJ, Liu Z, Khamaisi M, et al. Diabetic microvascular disease: an Endocrine Society scientific statement. J Clin Endocrinol Metab. 2017;102:4343-410.

34. Sun L, Yagoda S, Xue H, et al. Combination of olanzapine and samidorphan has no clinically relevant effects on ECG parameters, including the QTc interval: results from a phase 1 QT/QTc study. Prog Neuropsychopharmacol Biol Psychiatry. 2020;100:109881. 